\title{
Barriers to and facilitators of HIV serostatus disclosure to sexual partners among postpartum women living with HIV in South Africa
}

Oladele Vincent Adeniyi ${ }^{* *}$ (D, Charlotte Nwogwugwu ${ }^{2}$, Anthony Idowu Ajayi ${ }^{3}$ and John Lambert ${ }^{4}$

\begin{abstract}
Background: Disclosure of HIV serostatus to a sexual partner can facilitate partner's support and testing and better treatment outcomes. Studies examining changes in disclosure rates of serostatus from delivery and postpartum periods are scarce. Our study fills this gap by using a follow-up survey of postpartum women with HIV to examine if disclosure prevalence has improved compared to the proportion recorded at childbirth. We further assessed the reasons for non-disclosure and correlates of serostatus disclosure to sexual partners.

Methods: We conducted a cross-sectional analytical study (exit interview) with a final sample of 485 postpartum women with HIV drawn from the East London Prospective Cohort study database between January and May 2018. Disclosure of HIV status to partner was based on self-reporting. We fitted adjusted and unadjusted logistic regression models and also conducted descriptive statistical analyses. Sampling weights were used to correct for sampling errors.

Results: Overall, $81.8 \%$ of women in the study cohort had disclosed their status to their partners, representing a 7.4 percentage point increase since child delivery. After adjusting for important covariates, women were more likely to disclose their status if they were married [adjusted odds ratio (AOR): 3.10; 95\% confidence interval (Cl):1.39-6.91] but were less likely to disclose if they used alcohol [AOR: $0.61 ; 95 \%$ Cl:0.37-0.99] or had reported adherence to ART [AOR: 0.59; 95\% Cl:0.36-0.96]. Fear of rejection, stigma or being judged, new or casual relationships, and having a violent partner were the main reasons for not disclosing HIV status to sexual partners.

Conclusion: We found a relatively higher rate of HIV status disclosure in the cohort compared to the rate recorded at childbirth, suggesting an improvement over time. Also, complicated relationship dynamics and fear of social exclusion still constitute barriers to HIV status disclosure to sexual partners despite patients' counselling.
\end{abstract}

Keywords: Disclosure, Open communication, Relationship status, HIV status, South Africa

\footnotetext{
*Correspondence: vincoladele@gmail.com; oadeniyi@wsu.ac.za;

oadeniyi@gmail.com

'Department of Family Medicine \& Rural Health, Faculty of Health Sciences,

Walter Sisulu University, Mthatha/East London Hospital Complex, Cecilia

Makiwane Hospital, East London, South Africa

Full list of author information is available at the end of the article
}

(C) The Author(s). 2021 Open Access This article is licensed under a Creative Commons Attribution 4.0 International License, which permits use, sharing, adaptation, distribution and reproduction in any medium or format, as long as you give appropriate credit to the original author(s) and the source, provide a link to the Creative Commons licence, and indicate if changes were made. The images or other third party material in this article are included in the article's Creative Commons. licence, unless indicated otherwise in a credit line to the material. If material is not included in the article's Creative Commons licence and your intended use is not permitted by statutory regulation or exceeds the permitted use, you will need to obtain permission directly from the copyright holder. To view a copy of this licence, visit http://creativecommons.org/licenses/by/4.0/ The Creative Commons Public Domain Dedication waiver (http://creativecommons.org/publicdomain/zero/1.0/) applies to the data made available in this article, unless otherwise stated in a credit line to the data. 


\section{Background}

Disclosure of HIV serostatus has substantial implications for health outcomes, particularly in reaching the goal of an AIDS-free generation. Evidence shows that disclosure of HIV status promotes voluntary testing, safer sexual practices, and improves adherence to antiretroviral therapy (ART) [1]. HIV status disclosure has also been linked to positive mental health outcomes as social support from family and social networks has been shown to improve psychological well-being [2]. However, despite the documented benefits of serostatus disclosure, rates of disclosure to partners vary widely in sub-Saharan Africa. Among pregnant and postpartum African women living with HIV, disclosure rates to any individual range between 5 and $97 \%$, and to male partners, rates range between 30 and 93\% [3].

While it is critical that people living with HIV disclosed their status to their partner, stigma-both real and perceived - and social exclusion of people with HIV may hinder disclosure of status [4-6]. Fear of abandonment and sex deprivation, emotional abuse, intimate partner violence [7-9] results in non-disclosure of HIV status to their partners. Non-disclosure is usually dependent on the woman's previous experience in terms of the direct observation of the maltreatment of others, which includes, but is not limited to, social ostracisation and gossiping $[5,6,10]$.

The Joint United Nations Programme on HIV/AIDS (UNAIDS) had set a target of having 95\% of people living with HIV knowing their serostatus, 95\% of people who know their status to receive treatment and $95 \%$ of people on HIV treatment have a suppressed viral load [11]. These are not lofty goals, but one achievable with political commitment and inclusive society that does not stigmatize persons living with HIV. Supporting postpartum women to disclose their status will in no small measure contribute to achieving these goals.

The postpartum period is crucial for implementing interventions targeting vertical HIV transmission through breastfeeding and horizontal transmission. Breastmilk transmission of HIV remains a major threat during the immediate postpartum period; thus, serostatus disclosure to partners will further enhance adherence support and reduce the risk of vertical transmission [2]. Besides, serostatus disclosure to partners would improve the adoption of safe sexual practices and partner testing, which are important strategies in preventing horizontal transmission at the community level $[2,12]$. Couple testing was adopted as one of several strategies for the prevention of mother-to-child transmission (PMTCT) in South Africa [13]; however, men often present late for HIV testing compared to women in the country [14]. Also, a high proportion of women (between 15 and 49 years) in South Africa are single (64\%) and may not be in committed or long-term relationships $[15,16]$. Therefore, strengthening of serostatus disclosure to partners through counselling and education of women would further consolidate the goal of PMTCT.

In South Africa, further counselling on HIV disclosure is offered after delivery to strengthen ART adherence and prevent HIV transmission as per the PMTCT guidelines [13]. While several studies have investigated the prevalence and correlate of serostatus disclosure in South Africa $[1,3,15,17-20]$, we did not find a study that followed up a cohort of women to track improvement in the rate of disclosure to partners over a period of time. We conducted a follow-up (exit interview) study of the women enrolled in the East London Prospective Cohort Study in the Eastern Cape, South Africa, to fill this gap. We also examined reasons for non-disclosure and correlates of status disclosure to a sexual partner. These findings might shed light on the context in which disclosure decisions occur in South Africa to develop interventions that support women in making decisions about HIV disclosure during a vulnerable period of their lives. These findings could also highlight new avenues to tackle the barriers mitigating against HIV serostatus disclosure for the broader population of people living with HIV.

\section{Methods}

\section{Study design and settings}

This cross-sectional analytical study (follow-up exit interview) was conducted between January to May 2018 on a sample of parturient women with HIV enrolled in the electronic database of the East London Prospective Cohort Study [21]. All pregnant women attending maternity service would have received HIV testing, commenced on ART if diagnosed with HIV, and documented in the antenatal medical records per the PMTCT guidelines [13]. An electronic database was created for research purposes by the investigators between September 2015 and May 2016 to track the PMTCT outcomes of parturient women with HIV and their infants in three hospitals in Buffalo City and the Amathole district of the East Cape Province of South Africa. These hospitals serve a combined population of 1.7 million people residing in the rural and urban communities of the central region of the Eastern Cape [22].

\section{Participants and sample size}

The sample size for this sub-study (exit interview) was estimated as 485 , using the Cochran formula for categorical data, at a confidence level of $95 \%$, a precision level of $+/-4$ and $10 \%$ possible attrition. All the women enrolled in the East London Prospective Cohort Study database $(N=1709)$ signed informed consent at the baseline to be contacted for the follow-up (exit) study. However, only those who were accessible telephonically were considered eligible for this follow-up survey. Each 
participant was offered a choice to either complete an interviewer-guided interview face-to-face or telephonically. A few participants $(n=43)$ who chose to attend interviews at one of the three hospitals were reimbursed for transportation costs. Those who chose to complete telephonic interviews agreed to a scheduled time with our research team. A convenience sampling of the participants who were available and willing to participate was conducted.

We employed and trained two research assistants, who were fluent in both IsiXhosa (local language) and English for this study. The research team successfully contacted 509 participants out of a total of 1709 participants (29.9\%). Some of the eligible participants were no longer accessible through any of the three contactable mobile numbers obtained from the electronic database. We designed a questionnaire specifically for the exit interview, which was piloted with 12 parturient women with HIV in one of the hospitals to ascertain the validity and reliability of the instrument. We subsequently adjusted the questionnaire using feedback from the participants and the investigators.

\section{Measures}

With the aid of a validated questionnaire (Supplementary 1), outcome (dependent) and independent variables were obtained from the interview. These variables were informed by the existing knowledge in the literature and are described briefly.

\section{Outcome variable}

The key outcome variable for this study was disclosure of HIV to a sexual partner, and this was measured by asking the participants if they had disclosed their serostatus to their sexual partners. Responses were categorized as "yes" or "no" which was coded as 1 for 'yes' and 2 for 'no'. Also, we used an open-ended question to elicit information on the reasons for non-disclosure.

\section{Independent variables}

Socio-demographic, lifestyle behaviours and clinical characteristics were the covariates included in this study. The selection of these covariates was based on the existing knowledge of HIV disclosure in the literature [8-11].

\section{Socio-demographic characteristics}

We obtained information on the participants' ages which were coded as continuous variables, level of education, and marital status. We obtained information on the employment status of the participants, occupation in the preceding 12 months at the time of the study, and whether they were engaged in a salary-paying job. We obtained additional information on whether participants were receiving child support grants (social grants) from the South African government.

\section{Lifestyle behaviours}

We obtained information on the smoking status and alcohol consumption as categorical data with "yes" or "no" response, which was coded as 1 for 'yes' and 2 for 'no'. Smoking status was obtained by self-report of cigarette or any tobacco product within the preceding month of the study. Similarly, the consumption of any alcoholic beverage in the prior month of the study was obtained by self-report and recorded.

\section{Clinical characteristics}

The following clinical information was obtained through self-reporting by the participants: awareness of partner's HIV serostatus and complete adherence to ART (no missed dose of ART in the preceding week of the study). A binary response of "yes" or "no" was provided for the participants, which was coded as 1 for 'yes' and 2 for 'no'. We also documented the duration of HIV infection (period since diagnosis) among the participants, which was categorized as a continuous variable. We asked participants to provide open responses to reasons for not disclosing their status to their respective partners.

\section{Data analysis}

Data analysis was performed on responses from 485 out of 509 participants contacted (95.3\%). Of the 24 participants excluded in the analysis, nine were not interested in discussing their HIV serostatus and thus, withdrew during the interview. Six participants refused to participate in the exit interview, and nine were confirmed to have died by the family member who responded to the phone call. Disclosure of HIV serostatus to sexual partners was the main outcome measure of this study. Complete responses were available for 485 respondents on the main outcome measure and were included in this analysis. All analyses were conducted with the IBM Statistical Products and Service Solutions, version 27.0 (SPSS, Chicago, IL, USA). Given that this data is a convenient sample of the 1709 women with HIV who gave birth between September 2015 and May 2016 in the three largest health facilities in Eastern Cape, South Africa, we calculated sampling weight using respondents' age distributions. We applied the sampling weight for all analyses.

Descriptive statistics (means, frequency, and percentages) were used to summarise the characteristics of the participants disaggregated by their disclosure status. Given that the main outcome variable is dichotomous ("yes or no") and there are many explanatory variables, we performed adjusted and unadjusted logistic regression models to determine the independent and significant influencing factors of non-disclosure in the study. 
Variables were included in the final model if they have been shown by previous studies to influence disclosure of status significantly. Knowing partner status was positively correlated with the outcome variable and was therefore removed from the multivariate analysis. Also, smoking behaviour was highly related to alcohol use and was removed from the model. The 95\% confidence intervals were reported for all analyses, and $p$-values less than 0.05 were considered statistically significant.

\section{Results}

\section{Socio-demographic characteristics}

The average age of participants was $30.07 \pm 5.85$ years. Most participants were single (78.9\%), had up to grade 12 levels of education (88.6\%), were unemployed (71.3\%), but received social grants $(92.9 \%)$. The majority of the participants knew their partner's HIV status (65.2\%), did not smoke cigarettes in the past month (90.6\%), had consumed alcoholic beverages in the past month (63.2\%), had been living with HIV for 1 to 5 years (53.2\%) and self-reported complete adherence to ART (58.6\%) (Table 1).

\section{Level of serostatus disclosure to partners}

A total of 397 participants (81.8\%) had disclosed their HIV serostatus to their partners. However, the proportion of respondents who had disclosed their status varies by age, marital status, alcohol use, and knowing a partner's status. The HIV disclosure rate was highest among women who were married (92.2\%), had higher education (88.2\%), knew their partner's status (97.5\%), and selfreported complete ART adherence (86.0\%) (Table 2).

\section{Factors influencing HIV serostatus disclosure}

We used adjusted and unadjusted logistic regression models to examine the factors influencing HIV serostatus disclosure to a sexual partner. We included demographic, behavioural, and clinical factors in the model based on previous studies indicating that these factors were associated with disclosure of HIV status [1, 3, 15, 17-20]. However, we removed knowing partner's HIV status from the model due to colinearity with the disclosure of HIV status. Also, we removed smoking due to colinearity with alcohol use. In the adjusted regression, being married [unadjusted odds ratio (UOR): 3.29, 95\% confidence interval (CI) 1.51-7.13] was associated with increased odds of HIV serostatus disclosure to partner, while alcohol use (COR: 0.51, 95\% CI 0.32-0.81) and adherence to ART (UOR: 0.52, 95\% CI: 0.33-0.83) were associated with reduced odds of HIV serostatus disclosure (Table 3). The magnitude and direction of the effects of these variables remain in the adjusted model. Married women were three times more likely to disclose their status to their partners relative to single women.
However, alcohol users were $39 \%$ less likely to disclose their status compared to non-users of alcohol. Women who reported adherence to ART were $41 \%$ less likely to disclose their status.

\section{Reasons for non-disclosure}

The main reasons for not disclosing HIV serostatus to sexual partners were: lack of readiness, fear of rejection and violent reaction from the partner, fear of breaking up the relationship and being in a casual relationship (Table 4). Women who had not disclosed their status were seriously concerned about how their partner will react if they were to learn of their status, fearing rejection and violence against them. As a result, nondisclosure is seen as beneficial, enabling them to maintain peace and protect their relationships. Their fear of partner violence is not only perceived but real, as a few participants had observed their partner say unpleasant things or expressed judgemental attitudes about people living with HIV.

When asked why she had not disclosed her status, one participant responded: "I am afraid to tell because he says nasty things about people with HIV". Also, a few others were experiencing emotional abuse in their relationship at the time of the study, heightening their fear of possible violence if they disclosed their status. In contrast, some were in new relationships and did not consider themselves to be close enough to share such private information with their partners. While others simply did not know how to broach such a topic with their partners because they just do not talk about such a subject. Lastly, some women believed that they do not need to disclose their status because they were in relationships with no prospects and revealing such information was unnecessary.

\section{Discussion}

Given the dynamic nature of HIV serostatus disclosure to significant others, especially a sexual partner, it is crucial to examine the extent to which disclosure had improved over a period of time and its influencing factors among the women enrolled in the East London Prospective Cohort Study in the Eastern Cape, South Africa. To our knowledge, this is the first study from the Eastern Cape province, South Africa, to follow up a cohort of postpartum women with HIV. Therefore, this study provides new insights into the contextual factors that influence serostatus disclosure to sexual partners in the region, which might guide interventions for the broader population of people living with HIV.

This study reports a serostatus disclosure rate of 81.8\%. Given that HIV disclosure is an independent predictor of ART adherence, which mediates viral suppression $[12,20,23]$, the disclosure rate reported in this 
Table 1 Demographic and clinical characteristics of study participants

\begin{tabular}{|c|c|c|c|c|}
\hline Variables & Unweighted frequency & Unweighted proportions & Weighted frequencies & Weighted proportions \\
\hline All & 485 & 100 & 486 & 100 \\
\hline \multicolumn{5}{|l|}{ Age } \\
\hline 24 years and less & 36 & 7.4 & 112 & 23.0 \\
\hline 25-29years & 114 & 23.5 & 131 & 27.0 \\
\hline 30-34 years & 144 & 29.7 & 130 & 26.7 \\
\hline $35-39$ years & 123 & 25.4 & 86 & 17.7 \\
\hline 40 years and above & 68 & 14.0 & 27 & 5.6 \\
\hline \multicolumn{5}{|l|}{ Marital status } \\
\hline Single & 359 & 74.0 & 384 & 78.9 \\
\hline Married & 126 & 26.0 & 102 & 21.1 \\
\hline \multicolumn{5}{|l|}{ Education level } \\
\hline Grade 7 and less & 30 & 6.2 & 21 & 4.3 \\
\hline Grade 8-12 & 421 & 86.8 & 431 & 88.6 \\
\hline Higher education & 34 & 7.0 & 34 & 7.1 \\
\hline \multicolumn{5}{|l|}{ Employed in a salary paying job } \\
\hline Yes & 157 & 32.4 & 139 & 28.7 \\
\hline No & 328 & 67.6 & 347 & 71.3 \\
\hline \multicolumn{5}{|l|}{ Occupation in last 12 months } \\
\hline Government employee & 17 & 3.5 & 14 & 2.8 \\
\hline Non-government employee & 114 & 23.5 & 103 & 21.2 \\
\hline Self-employed & 29 & 6.0 & 26 & 5.4 \\
\hline Student & 23 & 4.7 & 44 & 9.1 \\
\hline Unemployed & 302 & 62.3 & 299 & 61.5 \\
\hline \multicolumn{5}{|c|}{ Receives government social grant } \\
\hline Yes & 453 & 93.6 & 451 & 92.9 \\
\hline No & 31 & 6.4 & 35 & 7.1 \\
\hline \multicolumn{5}{|l|}{ Smoked in the past month } \\
\hline Yes & 43 & 8.9 & 46 & 9.4 \\
\hline No & 442 & 91.1 & 440 & 90.6 \\
\hline \multicolumn{5}{|l|}{ Drank alcohol in the past month } \\
\hline Yes & 173 & 35.7 & 307 & 63.2 \\
\hline No & 312 & 64.3 & 179 & 36.8 \\
\hline \multicolumn{5}{|l|}{ Knows partner's serostatus } \\
\hline Yes & 319 & 65.8 & 317 & 65.2 \\
\hline No & 166 & 34.2 & 169 & 34.8 \\
\hline \multicolumn{5}{|l|}{ Year since HIV diagnosis } \\
\hline $1-5$ years & 206 & 42.5 & 259 & 53.2 \\
\hline $6-10$ years & 163 & 33.6 & 145 & 29.8 \\
\hline $11-17$ years & 116 & 23.9 & 83 & 17.0 \\
\hline \multicolumn{5}{|l|}{ Complete adherence } \\
\hline Yes & 310 & 63.9 & 285 & 58.6 \\
\hline No & 175 & 36.1 & 201 & 41.4 \\
\hline
\end{tabular}

Source: Exit interview of the East London Prospective Cohort Study done (2018) 
Table 2 Weighted Pearson Chi-square analysis of factors associated with HIV status disclosure among postpartum women with HIV

\begin{tabular}{|c|c|c|c|}
\hline Variables & Disclosed serostatus to partner & Had not disclosed serostatus to partner & $p$-value \\
\hline All & $397(81.8)$ & $89(18.2)$ & \\
\hline \multicolumn{4}{|l|}{ Age } \\
\hline 24 years and less & $84(75.0)$ & $28(25.0)$ & \multirow[t]{5}{*}{0.182} \\
\hline 25-29years & $113(86.3)$ & $18(13.7)$ & \\
\hline 30-34 years & $110(84.6)$ & $20(15.4)$ & \\
\hline $35-39$ years & $69(80.2)$ & $17(19.8)$ & \\
\hline 40 years and above & $22(78.6)$ & $6(21.4)$ & \\
\hline \multicolumn{4}{|l|}{ Marital status } \\
\hline Single & $303(78.9)$ & $81(21.1)$ & \multirow[t]{2}{*}{0.001} \\
\hline Married & $95(92.2)$ & $8(7.8)$ & \\
\hline \multicolumn{4}{|l|}{ Education level } \\
\hline Grade 7 and less & $18(85.7)$ & $3(14.3)$ & \multirow[t]{3}{*}{0.531} \\
\hline Grade 8-12 & $350(81.2)$ & $81(18.8)$ & \\
\hline Higher education & $30(88.2)$ & $4(11.8)$ & \\
\hline \multicolumn{4}{|l|}{ Employed in a salary paying job } \\
\hline Yes & $107(77.0)$ & $32(23.0)$ & \multirow[t]{2}{*}{0.053} \\
\hline No & $290(83.8)$ & $56(16.2)$ & \\
\hline \multicolumn{4}{|l|}{ Occupation in last 12 months } \\
\hline Government employee & $9(64.3)$ & $5(35.7)$ & \multirow[t]{5}{*}{0.0116} \\
\hline Non-government employee & $82(79.6)$ & $21(20.4)$ & \\
\hline Self-employed & $22(84.6)$ & $4(15.4)$ & \\
\hline Student & $32(72.7)$ & $12(27.3)$ & \\
\hline Unemployed & $253(84.6)$ & $46(15.4)$ & \\
\hline \multicolumn{4}{|l|}{ Receives government social grant } \\
\hline Yes & $366(81.0)$ & $86(19.0)$ & \multirow[t]{2}{*}{0.099} \\
\hline No & $31(91.2)$ & $3(8.8)$ & \\
\hline \multicolumn{4}{|l|}{ Smoking in the past month } \\
\hline Yes & $33(73.3)$ & $12(26.7)$ & \multirow[t]{2}{*}{0.119} \\
\hline No & $364(82.7)$ & $76(17.3)$ & \\
\hline \multicolumn{4}{|l|}{ Drank alcohol in the past month } \\
\hline Yes & $134(75.3)$ & $44(24.7)$ & \multirow[t]{2}{*}{0.003} \\
\hline No & $263(85.7)$ & $44(14.3)$ & \\
\hline \multicolumn{4}{|l|}{ Knows partner's serostatus } \\
\hline Yes & $309(97.5)$ & $8(2.5)$ & \multirow[t]{2}{*}{$<0.001$} \\
\hline No & $88(52.1)$ & $81(47.9)$ & \\
\hline \multicolumn{4}{|l|}{ Year since HIV diagnosis } \\
\hline $1-5$ years & $208(80.3)$ & $51(19.7)$ & \multirow[t]{3}{*}{0.415} \\
\hline $6-10$ years & $118(81.4)$ & $27(18.6)$ & \\
\hline $11-17$ years & $72(86.7)$ & $11(13.3)$ & \\
\hline \multicolumn{4}{|l|}{ Complete adherence } \\
\hline Yes & $245(86.0)$ & $40(14.0)$ & \multirow[t]{2}{*}{0.004} \\
\hline No & $153(76.1)$ & 48 (23.9) & \\
\hline
\end{tabular}

Source: Exit interview of the East London Prospective Cohort Study done (2018) 
Table 3 Adjusted and unadjusted logistic regression models showing the correlates of HIV serostatus disclosure to sexual partner

\begin{tabular}{|c|c|c|}
\hline Variables & Unadjusted Odds ratios & Adjusted Odds ratios \\
\hline \multicolumn{3}{|l|}{ Marital status } \\
\hline Married & $3.29(1.51-7.13)^{*}$ & $3.10(1.39-6.91)^{*}$ \\
\hline Single & 1 & 1 \\
\hline \multicolumn{3}{|l|}{ Age } \\
\hline 18-34 years & $1.14(0.67-1.95)$ & $1.66(0.89-3.11)$ \\
\hline $35-46$ years & 1 & 1 \\
\hline \multicolumn{3}{|l|}{ Education level } \\
\hline Grade 7 and less & $0.89(0.18-4.34)$ & $0.52(0.10-2.78)$ \\
\hline Grade 8-12 & $0.63(0.23-1.77)$ & $0.58(0.20-1.67)$ \\
\hline Higher education & 1 & 1 \\
\hline \multicolumn{3}{|c|}{ Employed in a salary paying job } \\
\hline Yes & $0.64(0.40-1.05)$ & $0.67(0.40-1.12)$ \\
\hline No & 1 & 1 \\
\hline \multicolumn{3}{|c|}{ Drank alcohol in the past year } \\
\hline Yes & $0.51(0.32-0.81)^{*}$ & $0.61(0.37-0.99)^{*}$ \\
\hline No & 1 & \\
\hline \multicolumn{3}{|c|}{ Year since HIV diagnosis } \\
\hline $1-5$ years & $0.60(0.29-1.22)$ & $0.62(0.28-1.40)$ \\
\hline $6-10$ years & $0.65(0.30-1.39)$ & $0.65(0.29-1.48)$ \\
\hline $11-17$ years & 1 & 1 \\
\hline \multicolumn{3}{|l|}{ Complete adherence } \\
\hline Yes & $0.52(0.33-0.83)^{*}$ & $0.59(0.36-0.96)^{*}$ \\
\hline No & 1 & 1 \\
\hline
\end{tabular}

study is commendable. Status disclosure to partners should be strengthened to prevent further transmission during the postpartum period (HIV breastmilk transmission) in the region by consolidating the counselling sessions at the postnatal clinics. As previously reported, non-disclosure is strongly associated with high viral load whilst on ART [12, 20,23] and increased risk of HIV transmission to infants through the breastmilk. The high rate of disclosure in the present study $(81.8 \%)$ is higher than the rate $(74.4 \%)$ reported in the same population

Table 4 Reasons for non-disclosure of HIV serostatus

\begin{tabular}{lll}
\hline Reasons for not disclosing serostatus & $\begin{array}{l}\text { Frequency } \\
\mathbf{n = 8 9}\end{array}$ & Percentage \\
\hline Fear of rejection and violent reaction & 14 & 16.5 \\
Broke up with him & 10 & 11.8 \\
Not ready to tell him & 55 & 64.7 \\
Not that close to him to discuss such topic & 6 & 7.8 \\
\hline
\end{tabular}

Source: Exit interview of the East London Prospective Cohort Study done (2018) during the antenatal period by Adeniyi et al. [15]. Similar disclosure rates were reported in the literature among pregnant and postpartum women in France, Tanzania and Pretoria, South Africa [17, 18, 24]. Given that HIV status disclosure is a dynamic process that evolves over a period of time $[2,25]$, the present study reports a seven-point increase in the disclosure rate observed after 24 months post-delivery. This further demonstrates that individuals living with HIV become more open and comfortable with their partners, thus, facilitating discussion about their status $[18,26]$.

Our results show that being married was associated with increased odds of HIV status disclosure. Participants who had not disclosed their status indicated that they had broken up the relationship with their partner or were not close enough to warrant disclosure of HIV status. This finding is similar to previous studies conducted in Tanzania, Ethiopia, Kenya, and Burkina Faso $[7,10,19,27]$. Daily contact in marital relationships might increase the likelihood of HIV status disclosure compared to single women who may not necessarily be committed to the relationship. The dynamics in the relationship status of women with HIV in the region are unique. The majority were single (74\%) and as reported in the qualitative component; some of these women did not envisage a future with the current partner, some consider their relationships as casual and others felt that they had not attained the level of closeness to broach the topic of HIV status with their partner. It is, therefore, imperative for clinicians and programme managers to provide the necessary support for single women with HIV. Given that a large proportion (64\%) of women between 15 and 49 years are single in South Africa [16], context-specific interventions should be crafted to promote serostatus disclosure in this vulnerable population in the region.

Surprisingly, the duration of the infection did not influence the disclosure rate observed in this study, as the majority of the participants $(57.5 \%)$ had been diagnosed more than 5 years at the time of this survey. Nevertheless, all participants had been diagnosed with HIV for over 2 years, suggesting that they had had sufficient time to process their HIV status and decide on who and when to disclose their status. Perhaps, the length of the relationship with a current partner might shed light on the association between infection duration and disclosure of HIV status. Whether the change of sexual partners after the diagnosis mediated the association between HIV status' disclosure and duration of infection is unclear in this study.

Behavioural challenges such as alcohol use and adherence to ART were associated with non-disclosure in this study. Findings on the influence of alcohol on nondisclosure of status are mixed, with some studies reporting no significant association [28-30] and others 
reporting positive association [15]. Regardless of the previous reports, any individual who does not disclose his/ her serostatus and continues to practice unprotected sex [31], which is very common among alcohol users, is highly likely to transmit HIV. To prevent new infections at the community level; whether vertical (in the postpartum period) or horizontal transmission, disclosure to sexual partners must be encouraged and prioritized by public health officials. The relationship between ART adherence and disclosure of HIV serostatus is well established. Hence, this finding supports previous reports on disclosure and ART adherence [12, 20, 23]. The PMTCT guidelines should therefore focus on encouraging women to disclose their status with a view of promoting couple testing [13].

Reasons for non-disclosure among the participants were fear of rejection and partners' violent reactions and not being ready to disclose. These are consistent with previous studies in a similar setting in South Africa [15] and elsewhere [17, 32]. Addressing these reasons through counselling might help facilitate the disclosure of HIV status to partners. The ultimate goal of status disclosure is to motivate partners to get tested for HIV and access treatment if tested positive, which is in line with the UNAIDS 95-95-95 goal of achieving an HIVfree generation. Also, achieving undetectable viral load levels has been proven to eliminate the chances of HIV transmission with the Undetectable $=$ Untransmittable campaign [33]. Educating the public on this important advancement in HIV treatment will help to reduce stigma and facilitate HIV disclosure and testing [33].

\section{Study limitations}

The cross-sectional nature of the data limits the determination of the temporal nature of the associations reported in this study. Also, a large proportion of the women were no longer accessible, which may impact the representativeness of the participants in this study. The outcome variable was measured by self-reporting; as such, social desirability and recall bias cannot be excluded entirely, though this is a common phenomenon. Nevertheless, this study provides essential insights into the influencing factors of serostatus disclosure by the broader population of women living with HIV and other populations in the region. Findings will guide health authorities to develop strategies to provide HIV prevention programmes in this population and the broader population of people living with HIV in the region.

\section{Conclusions}

We found a relatively higher rate of HIV status disclosure in the study population compared to the rate recorded at childbirth suggesting that individuals living with HIV become more open and comfortable with their partners over time, thus, facilitating discussion about their status. Also, complicated relationship dynamics still present barriers to HIV status disclosure to sexual partners in this region. Clinicians' counselling and education should focus on strengthening open communication between partners to improve status disclosure, HIV treatment outcomes and further prevent vertical transmission in this region. Intervention strategies should be tailored for single women with HIV to promote HIV disclosure, improve ART adherence, and, consequently, decrease transmission at the community level.

\section{Abbreviations}

AIDS: Acquired immune deficiency syndrome; ART: Anti-retroviral therapy; HIV: Human immunedefimmunodeficiency; MTCT: Prevention of mother-tochild transmission; SSA: Sub-Saharan Africa

\section{Supplementary Information}

The online version contains supplementary material available at https://doi. org/10.1186/s12889-021-10955-x.

Additional file 1. PMTCT Questionnaire (Adeniyi, et al., 2018).

\section{Acknowledgments}

We thank the management of Bisho, Cecilia Makiwane and Frere Hospitals in the Eastern Cape. We express appreciation to Ms. Tembisa Sizani, Mrs. Talita Plaatjie, Mrs. Nkosazana Jwacu, and Ms. Rosemond Billie for their support.

\section{Authors' contributions}

OVA, AIA and JL conceptualized, designed, and implemented the study protocol. OVA and JL supervised data collection. CN and OVA drafted the manuscript, and AIA performed the analysis. All authors reviewed, revised, and approved the draft for submission.

\section{Funding}

The South African AIDS Vaccine Initiative supported this project under the auspices of the South African Medical Research Council [Grant Number: SAMR C/03/2017] with funds received from the South African National Department of Health and awarded to OVA. Funders have no direct involvement in the conception and implementation of the project or content of the manuscripts.

\section{Availability of data and materials}

All data and materials used for this study are available with the corresponding author upon reasonable request.

\section{Declarations}

Ethics approval and consent to participate

Ethical approval was granted by the Walter Sisulu University's Ethics Committee (Reference: 085/2017). The Eastern Cape Department of Health and the management of the hospitals granted permission to implement the study. Though the participants had signed written informed consent at the baseline for a follow-up study, we obtained another informed consent either verbally for a telephonic interview or in writing (at the face-to-face interviews). Each participant understood her right to participate and to refuse to answer any question; she was also made aware that if she was not comfortable with the interview or process, she had the right to even drop out at any stage of the interview. Participants' rights to privacy and confidentiality of medical information were respected throughout the study period.

Consent for publication

Not applicable.

\section{Competing interests}

AIA - is an associate editor of the BMC Public Health journal. Other authors have no conflict of interest to declare. 


\section{Author details}

'Department of Family Medicine \& Rural Health, Faculty of Health Sciences, Walter Sisulu University, Mthatha/East London Hospital Complex, Cecilia Makiwane Hospital, East London, South Africa. ${ }^{2}$ Masters in Public Health Program, UMB School of Medicine, University of Maryland School of Nursing, 655 West Lombard St., Room 482, Baltimore, MD 21201, USA. ${ }^{3}$ Population Dynamics and Sexual and Reproductive Health, African Population and Health Research Centre, APHRC Campus, Manga Close, Nairobi, Kenya. ${ }^{4}$ Mater Misericordiae University Hospital and University College Dublin School of Medicine, Dublin, Ireland.

Received: 25 April 2020 Accepted: 3 May 2021 Published online: 13 May 2021

\section{References}

1. Hampanda KM, Rael CT. HIV status disclosure among postpartum women in Zambia with varied intimate partner violence experiences. AIDS Behav. 2018;22(5):1652-61. https://doi.org/10.1007/s10461-017-1909-0.

2. Brittain $\mathrm{K}$, Mellins CA, Remien RH, Phillips T, Zerbe A, Abrams EJ, et al. Patterns and predictors of HIV-status disclosure among pregnant women in South Africa: dimensions of disclosure and influence of social and economic circumstances. AIDS Behav. 2018;22(12):3933-44. https://doi.org/10.1007/s1 0461-018-2263-6.

3. Tam M, Amzel A, Phelps BR. Disclosure of HIV serostatus among pregnant and postpartum women in sub-Saharan Africa: a systematic review. AIDS Care. 2015;27(4):436-50. https://doi.org/10.1080/09540121.2014.997662.

4. Medley A, Garcia-Moreno C, McGill S, Maman S. Rates, barriers and outcomes of HIV serostatus disclosure among women in developing countries: implications for prevention of mother-to-child transmission programmes. Bull World Health Organ. 2004;82(4):299-307.

5. Olley B, Ogunde M, Oso P, Ishola A. HIV-related stigma and self-disclosure: the mediating and moderating role of anticipated discrimination among people living with HIV/AIDS in Akure Nigeria. AIDS Care. 2016;28(6):726-30. https://doi.org/10.1080/09540121.2016.1140894.

6. Visser MJ, Neufeld S, De Villiers A, Makin JD, Forsyth BW. To tell or not to tell: South African women's disclosure of HIV status during pregnancy. AIDS Care. 2008;20(9):1138-45. https://doi.org/10.1080/09540120701842779.

7. Alemayehu M, Aregay A, Kalayu A, Yebyo H. HIV disclosure to sexual partner and associated factors among women attending ART clinic at Mekelle hospital, Northern Ethiopia. BMC Public Health. 2014;14(1):746. https://doi. org/10.1186/1471-2458-14-746.

8. Odiachi A, Erekaha S, Cornelius LJ, Isah C, Ramadhani HO, Rapoport L, et al. HIV status disclosure to male partners among rural Nigerian women along the prevention of mother-to-child transmission of HIV cascade: a mixed methods study. Reprod Health. 2018;15(1):36. https://doi.org/10.1186/s12 978-018-0474-y

9. Rujumba J, Neema S, Byamugisha R, Tylleskär T, Tumwine JK, Heggenhougen HK. "Telling my husband I have HIV is too heavy to come out of my mouth": pregnant women's disclosure experiences and support needs following antenatal HIV testing in eastern Uganda. J Int AIDS Soc. 2012;15(2):17429. https://doi.org/10.7448/ias.15.2.17429.

10. Kiula ES, Damian DJ, Msuya SE. Predictors of HIV serostatus disclosure to partners among HIV-positive pregnant women in Morogoro, Tanzania. BMC Public Health. 2013;13(1):433. https://doi.org/10.1186/1471-2458-13-433.

11. The Joint United Nations Programme on HIV/AIDS. Fast-track: ending the AIDS epidemic by 2030 in. Geneva: UNAIDS; 2014.

12. Trinh TT, Yatich N, Ngomoa R, McGrath CJ, Richardson BA, Sakr SR, et al. Partner Disclosure and Early CD4 Response among HIVInfected Adults Initiating Antiretroviral Treatment in Nairobi Kenya. PLoS ONE. 2016;11(10): e0163594. https://doi.org/10.1371/journal.pone.0163594.

13. Africa NDoHS. National Consolidated Guidelines for the Prevention of Mother-to-Child Transmission of HIV (PMTCT) and the management of HIV in children, adolescents and adults. Pretoria: Department of Health; 2015.

14. Sogbanmu OO, Goon DT, Obi LC, Iweriebor BC, Nwodo UN, Ajayi Al, et al. Socio-demographic and clinical determinants of late presentation among patients newly diagnosed with HIV in the Eastern Cape, South Africa. Medicine. 2019;98(8):e14664. https://doi.org/10.1097/MD.0000000000014664.

15. Adeniyi O, Ajayi A, Selanto-Chairman N, Goon D, Boon G, Fuentes Y, et al. Demographic, clinical and behavioural determinants of HIV serostatus nondisclosure to sex partners among HIV-infected pregnant women in the
Eastern Cape, South Africa. PLoS One. 2017;12(8):e0181730. https://doi.org/1 0.1371/journal.pone.0181730.

16. Health NDo, Africa SS, Council SAMR, ICF. South Africa demographic and health survey 2016. NDoH, Stats SA, SAMRC, and ICF Pretoria, South Africa, and Rockville ...; 2019.

17. Yonah G, Fredrick F, Leyna G. HIV serostatus disclosure among people living with HIV/AIDS in Mwanza, Tanzania. AIDS Res Ther. 2014;11(1):5. https://doi. org/10.1186/1742-6405-11-5.

18. Makin JD, Forsyth BW, Visser MJ, Sikkema KJ, Neufeld S, Jeffery B. Factors affecting disclosure in South African HIV-positive pregnant women. AIDS Patient Care STDs. 2008;22(11):907-16. https://doi.org/10.1089/apc.2007.0194.

19. Msuya SE, Mbizvo E, Hussain A, Uriyo J, Sam N, Stray-Pedersen B. Low male partner participation in antenatal HIV counselling and testing in northern Tanzania: implications for preventive programs. AIDS Care. 2008;20(6):700-9. https://doi.org/10.1080/09540120701687059.

20. Stirratt MJ, Remien RH, Smith A, Copeland OQ, Dolezal C, Krieger D, et al. The role of HIV serostatus disclosure in antiretroviral medication adherence. AIDS Behav. 2006;10(5):483-93. https://doi.org/10.1007/s10461-006-9106-6.

21. Adeniyi OV, Ajayi Al, Issah M, Owolabi EO, Ter Goon D, Avramovic G, et al. Beyond health care providers' recommendations: understanding influences on infant feeding choices of women with HIV in the Eastern Cape, South Africa. Int Breastfeed J. 2019;14(1):7. https://doi.org/10.1186/s13006-019-0201-5.

22. Statistics South Africa. Mid-year population estimates 2017. Salvokop: ISIbalo House; 2017.

23. Biadgilign S, Deribew A, Amberbir A, Deribe K. Barriers and facilitators to antiretroviral medication adherence among HIV-infected paediatric patients in Ethiopia: A qualitative study. Sahara J. 2009;6(4):148-54. https://doi.org/1 0.1080/17290376.2009.9724943.

24. Jasseron C, Mandelbrot L, Dollfus C, Trocmé N, Tubiana R, Teglas J, et al. Non-disclosure of a pregnant woman's HIV status to her partner is associated with non-optimal prevention of mother-to-child transmission. AIDS Behav. 2013;17(2):488-97. https://doi.org/10.1007/s10461-011-0084-y.

25. Obermeyer CM, Baijal P, Pegurri E. Facilitating HIV disclosure across diverse settings: a review. Am J Public Health. 2011;101(6):1011-23. https://doi.org/1 0.2105/AJPH.2010.300102.

26. Chaudoir SR, Fisher JD, Simoni JM. Understanding HIV disclosure: a review and application of the disclosure processes model. Soc Sci Med. 2011; 72(10):1618-29. https://doi.org/10.1016/j.socscimed.2011.03.028.

27. Nebié Y, Meda N, Leroy V, Mandelbrot L, Yaro S, Sombié I, et al. Sexual and reproductive life of women informed of their HIV seropositivity: a prospective cohort study in Burkina Faso. J Acquir Immune Defic Syndr. 2001;28(4):367-72

28. Conserve DF, King G, Dévieux JG, Jean-Gilles M, Malow R. Determinants of HIV serostatus disclosure to sexual partner among HIV-positive alcohol users in Haiti. AIDS Behav. 2014;18(6):1037-45. https://doi.org/10.1007/s10461-0130685-8.

29. D'Angelo LJ, Abdalian SE, Sarr M, Hoffman N, Belzer M, Network AMHAR. Disclosure of serostatus by HIV infected youth: the experience of the REACH study. J Adolesc Health. 2001;29(3):72-9. https://doi.org/10.1016/S1054-13 9X(01)00285-3.

30. Lunze K, Cheng DM, Quinn E, Krupitsky E, Raj A, Walley AY, et al. Nondisclosure of HIV infection to sex partners and alcohol's role: a Russian experience. AIDS Behav. 2013;17(1):390-8. https://doi.org/10.1007/s10461012-0216-z.

31. Mfecane S. Can women' refuse' condoms? Dilemmas of condom negotiation among men living with HIV in South Africa. Cult Health Sex. 2013;15(3):269-82. https://doi.org/10.1080/13691058.2012.729159.

32. Bachanas P, Medley A, Pals S, Kidder D, Antelman G, Benech I, et al. Disclosure, knowledge of partner status, and condom use among HIV-positive patients attending clinical care in Tanzania, Kenya, and Namibia. AIDS Patient Care STDs. 2013;27(7):425-35. https://doi.org/10.1089/apc.2012.0388.

33. Tobin SC. $U=U$ gains strength with release of PARTNER2 data. Aids. 2019; 33(3):N1. https://doi.org/10.1097/QAD.0000000000002098.

\section{Publisher's Note}

Springer Nature remains neutral with regard to jurisdictional claims in published maps and institutional affiliations. 